ORIGINAL ARTICLE

\title{
Occupational risk factors for pancreatic cancer among female textile workers in Shanghai, China
}

\author{
W Li, R M Ray, D L Gao, E D Fitzgibbons, N S Seixas, J E Camp, K J Wernli, \\ G Astrakianakis, Z Feng, D B Thomas, H Checkoway
}

See end of article for authors' affiliations ....................

Correspondence to: Dr W Li, Epidemiology Program, Public Health Sciences, Fred Hutch Cancer Research Center, 1100 Fairview Avenue North, Building M4-A402, PO Box 19024, Seattle WA, 98109, USA; wli@ fhcrc.org

Accepted 23 June 2006 Published Online First 17 July 2006

\begin{abstract}
Objectives: To investigate whether occupational exposures to dusts and chemicals in the Shanghai textile industry are associated with risk of pancreatic cancer.

Methods: A case cohort study nested in a cohort of 267400 female textile workers in Shanghai, China was conducted among 180 incident pancreatic cancer cases and an age stratified randomly selected comparison subcohort $(n=3188)$. A complete occupational history of work in the textile industry was obtained for each woman, and was linked to a job exposure matrix developed for the textile industry to estimate exposures to specific dusts and chemicals. Cumulative exposures to cotton dust and endotoxin were reconstructed from historical and contemporaneous measurements.

Results: After adjusting for smoking status, a trend of decreasing risk of pancreatic cancer was observed for increasing cumulative exposures to cotton dust and endotoxin with a lag of 20 years. The hazard ratios for women cumulatively exposed to $>143.4 \mathrm{mg} / \mathrm{m}^{3} \times$ years of cotton dust and $>3530.6 \mathrm{EU} / \mathrm{m}^{3} \times$ years of endotoxin were $0.6(95 \% \mathrm{Cl} 0.3$ to 0.9$)$ and $0.5(95 \% \mathrm{Cl} 0.3$ to 0.9$)$, respectively, compared to unexposed women. There was little evidence that exposures to other textile dusts and chemicals were associated with risk of pancreatic cancer.

Conclusions: Occupational exposure to cotton dust and endotoxin in the textile industry may have reduced risks of pancreatic cancer in this cohort. These associations should be replicated by others before making a firm conclusion of their possible effects on pancreatic cancer.
\end{abstract}

$\mathrm{P}$ ancreatic cancer is a rapid fatal malignancy. It is the fourth leading cause of cancer death in the United States. ${ }^{1}$ Cigarette smoking and diabetes are the well established risk factors for pancreatic cancer, although these two factors are thought to account for only small fraction of cases. ${ }^{2}$ The aetiology of pancreatic cancer remains largely unknown. Results of a meta-analysis of data from six case control and eight cohort studies indicated a weak association between obesity and the risk of pancreatic cancer. ${ }^{3}$ Increased risks of pancreatic cancer have been linked to various industries and occupations, including the chemical industry, ${ }^{45}$ printing, ${ }^{6-8}$ the metal industry, ${ }^{10}$ leather tanning, ${ }^{11-13}$ mechanics, ${ }^{14-16}$ and agricultural workers applying pesticides. $^{14}{ }^{17-20}$ A recent meta-analysis of 92 studies suggested increased risks of pancreatic cancer associated with occupational exposures to chlorinated hydrocarbon solvents and nickel compounds. ${ }^{21}$

Employment in the textile industry can entail exposures to various dusts (for example, cotton, wool, silk, and synthetic fibres) and chemicals (for example, dyes, inks, formaldehyde, and benzene). Several studies have linked employment in the textile industry to risk of pancreatic cancer. ${ }^{12} 152223 \mathrm{Ji}$ et al reported a non-significant increased risk of pancreatic cancer $(\mathrm{OR}=1.4)$ among women who have worked as a textile worker in a population based case control study conducted in Shanghai, China. Most of these studies are case control studies that were not conducted in industrial settings, and none considered specific exposures within the textile industry. We conducted a case cohort study nested in a cohort of 267400 female textile workers in Shanghai, China to investigate possible occupational risk factors for pancreatic cancer.

\section{METHODS}

\section{Cohort population and case definition}

The study population included 267400 female employees in 526 factories in the Shanghai Textile Industry Bureau (STIB) who had been enrolled from October 1989 to October 1991 in a randomised trial of breast self-examination (BSE). ${ }^{24}{ }^{25}$ All currently working and retired female employees, at the time of enrollment, who were born between 1 January 1925 and 31 December 1958 were eligible to participate in the trial. Thirty four former medical workers, who were trained to be BSE trial field workers, trained factory medical workers to administer a baseline questionnaire that elicited data on smoking, alcohol use, and reproductive history.

Both current and retired employees received routine health care through health clinics in their factories. A detailed description of incident cancer case finding and diagnostic confirmation has been presented previously. ${ }^{26}$ Briefly, all cancers diagnosed during 1989 and 1998 were reported by clinic workers to a cancer and death registry operated by the STIB Station for the Prevention and Treatment of Cancer. Cancer diagnoses were confirmed by computer matching with records from the Shanghai Cancer Registry and medical record review when no computer match was found. For this study, 186 women with primary pancreatic cancer (International Classification of Diseases 9th Revison (ICD9) codes 157.0, 157.1, 157.2, 157.9) were identified from the STIB cancer registry, and their diagnoses were subsequently confirmed by medical record review. Of the 186 pancreatic cases, $46(25 \%)$ were histologically confirmed; 3 (1.6\%) were

Abbreviations: $B S E$, breast self-examination; JEM, job exposure matrix STIB, Shanghai Textile Industry Bureau 
Table 1 Characteristics of cancer cases and non-cases at baseline

\begin{tabular}{|c|c|c|}
\hline & $\begin{array}{l}\text { Cases }(n=180), \\
n(\%)\end{array}$ & $\begin{array}{l}\text { Non-cases } \\
(n=3183), n(\%)\end{array}$ \\
\hline \multicolumn{3}{|l|}{ Year of birth } \\
\hline $1925-29$ & $73(40.6)$ & $935(29.4)$ \\
\hline 1930-34 & $65(36.1)$ & $916(28.8)$ \\
\hline 1935-39 & $19(10.6)$ & 366 (11.5) \\
\hline $1940-44$ & $10(5.6)$ & $163(5.1)$ \\
\hline $1945-49$ & $6(3.3)$ & $281(8.8)$ \\
\hline $1950-54$ & $6(3.3)$ & $322(10.1)$ \\
\hline $1955-58$ & $1(0.6)$ & $200(6.3)$ \\
\hline \multicolumn{3}{|l|}{ Marital status } \\
\hline Never married & $1(0.6)$ & $29(0.9)$ \\
\hline Married & $162(90.0)$ & $2894(90.9)$ \\
\hline Divorced & $2(1.1)$ & $22(0.7)$ \\
\hline \multirow{2}{*}{\multicolumn{3}{|c|}{ Alcohol consumption }} \\
\hline & & \\
\hline Never & $150(83.3)$ & $2608(81.9)$ \\
\hline$<1 /$ month & $18(10.0)$ & 432 (13.6) \\
\hline $1-3 /$ month & $1(0.6)$ & $49(1.5)$ \\
\hline 1/week & $6(3.3)$ & $25(0.8)$ \\
\hline $2+/$ week & $5(2.9)$ & $69(2.2)$ \\
\hline \multicolumn{3}{|l|}{ Smoking status } \\
\hline Never & $159(88.3)$ & 3039 (95.5) \\
\hline Former smoker & $5(2.8)$ & $26(0.8)$ \\
\hline \multirow{2}{*}{\multicolumn{3}{|c|}{$\begin{array}{l}\text { Current smoker } \\
\text { Number of live birth }\end{array}$}} \\
\hline & & \\
\hline 1 & $18(10.3)$ & $750(24.5)$ \\
\hline 2 & $30(17.1)$ & $573(18.7)$ \\
\hline$\geqslant 3$ & $127(72.6)$ & $1736(56.8)$ \\
\hline \multicolumn{3}{|c|}{ Age at first live birth } \\
\hline 19 or less & $23(13.1)$ & $266(8.7)$ \\
\hline $20-24$ & $83(47.4)$ & $1302(42.6)$ \\
\hline $25-29$ & $49(28.0)$ & $1154(37.7)$ \\
\hline 30 or older & $20(11.4)$ & $337(11.0)$ \\
\hline \multicolumn{3}{|c|}{ Daily oral contraceptive use } \\
\hline Never & $161(89.4)$ & $2764(86.8)$ \\
\hline Ever & $19(10.6)$ & 419 (13.2) \\
\hline
\end{tabular}

cytologically confirmed; 84 (45\%) were diagnosed by $x$ ray, CAT scan, or ultrasound.

\section{Case cohort design}

A case cohort study design was applied to explore associations between occupational exposures and risks of various cancers, including pancreatic cancer. ${ }^{27}$ A subcohort of 3199 women was randomly selected from the cohort for comparison with pancreatic and 14 other cancer case groups. The subcohort was frequency matched by five year age group to correspond to the age distribution of all cancers in the study. Five women with pancreatic cancer were also included in the subcohort. Follow up began at the time of enrollment in the BSE trial, and ended at the earliest of subjects' dates of cancer diagnosis, death, or transfer out of the STIB, or at the termination date of follow up on 31 December 1998.

\section{Exposure assessment}

The Shanghai textile industry is an integrated system and had, at one time, well over 500 factories and more than 550000 workers. Its production includes not only the manufacture of fibres, cloth, garment, but also the manufacture of textile production equipment and other support products for the industry. ${ }^{28}$ A complete occupational history, including employment dates, workshop, and task description in the textile industry, was collected for each of the study participants by 30 trained interviewers by abstracting the relevant information from employment records $(80.0 \%)$, or interviewing the woman's supervisor or co-workers (11.0\%). If the work history information was incomplete or unavailable from these sources, the woman was interviewed by telephone or in-person $(8.3 \%)$ following the same study protocol. The distribution of the methods used to collect work history among cases is similar to that among women in the subcohort. All of the contacted women agreed to be interviewed. We were able to obtain information of factory employment for 180 pancreatic cancer cases and 3188 subcohort women. These women were included in the analysis.

A team of six industrial hygienists used a standardised factory profile form to record for each factory the production processes, type of workshops, and historical measurements of hazardous exposures since the establishment of the factory. This information was obtained from the factory or from the district branch of the Shanghai Centers for Disease Control and Prevention.

A job exposure matrix (JEM) was developed specifically for the Shanghai textile industry, as described previously. ${ }^{29}$ The JEM was based on a composite of two sources: (1) an a priori assessment of exposures by process developed by US industrial hygienists to classify fibre/process combinations according to the likely presence of various categories of dusts, chemicals, and physical agents, and (2) the prevalence of exposures reported by Chinese industrial hygienists in specific textile processes within the factory. A process was considered a source of the exposure if exposure to a particular chemical or dust was reported with more than 30\% frequency. The industrial hygienists judged whether each specific process resulted in exposure to textile dusts (cotton, wool, silk, total natural fibres, synthetic fibre, and mixed fibre) and chemicals (solvents, bleaching agents, acids and bases, sulphuric acid, dyes, inks, resin monomers, formaldehyde, pesticides, and metals).

In addition, we obtained quantitative information on cotton dust and endotoxin exposures. Details of this assessment have been published..$^{30}$ Briefly, quantitative assessment of the cotton dust exposure was estimated for each specific textile process using historical measurements collected by industrial hygienists from 56 factories between 1975 and 1999. Endotoxin concentrations were estimated using the predicted cotton dust estimates and average concentrations of endotoxin per unit dust mass (EU/mg dust) in each major process from the respiratory disease studies conducted by Christiani $e a^{l^{31-33}}$ and from additional dust and endotoxin measurements made for this study. ${ }^{34}$ These quantitative estimates were combined with each subject's work history and information from the JEM to estimate cumulative historical exposures of cotton dust and endotoxin. The exposure assessment for all agents was made without knowledge of study subjects' disease status.

The study was approved by the Institutional Review Boards of the Fred Hutchinson Cancer Research Center and the Station for Prevention and Treatment of Cancer of the Shanghai Textile Industry Bureau, in accordance with an assurance filed with the Office for Human Research Protections (OHRP) of the US Department of Health and Human Services.

\section{Analysis}

We applied Cox proportional hazards modeling, adapted for the case-cohort design, for risk analyses (Stata version $8 \mathrm{SE}$, Stata Corporation, College Station, TX, USA). A weight of one was applied to all cases, and weights equal to the reciprocal of the sampling fractions were applied to all of the non-cases in the subcohort. The weighting was accounted for in the Cox regression by including the natural logarithm of the weight as an offset term in the model statement. In this way, an offset value of zero was assigned to all cancer cases since all cases have been sampled with the probability of one. ${ }^{35}$ The estimated association was the hazard ratio (HR) and its corresponding 95\% confidence interval (CI). The likelihood 


\begin{tabular}{|c|c|c|c|c|c|}
\hline $\begin{array}{l}\text { Duration of working in } \\
\text { each process }\end{array}$ & $\begin{array}{l}\text { Cases } \\
(n=180)\end{array}$ & $\begin{array}{l}\text { Non-cases } \\
(n=3183)\end{array}$ & $\mathrm{HR}^{*}$ & $95 \% \mathrm{Cl}$ & $p$ for trend \\
\hline \multicolumn{6}{|c|}{ Warehouse, packing, quality control } \\
\hline Never & 150 & 2663 & 1.0 & Ref & \\
\hline$<10$ years & 6 & 183 & 0.7 & $(0.3$ to 1.5$)$ & \\
\hline $10-20$ years & 9 & 147 & 1.2 & $(0.6$ to 2.5$)$ & \\
\hline$>20$ years & 15 & 190 & 1.4 & $(0.8$ to 2.4$)$ & 0.28 \\
\hline \multicolumn{6}{|c|}{ Cotton handing, processing, spinning } \\
\hline Never & 143 & 2587 & 1.0 & Ref & \\
\hline$<10$ years & 13 & 123 & 1.5 & (0.8 to 2.8 ) & \\
\hline $10-20$ years & 4 & 154 & 0.5 & $(0.2$ to 1.3$)$ & \\
\hline$>20$ years & 20 & 319 & 0.9 & $(0.5$ to 1.5$)$ & 0.43 \\
\hline \multicolumn{6}{|c|}{ Mixed fibre handling, processing, spinning } \\
\hline Never & 152 & 2741 & 1.0 & Ref & \\
\hline$<10$ years & 9 & 126 & 1.1 & (0.5 to 2.2 ) & \\
\hline $10-20$ years & 8 & 115 & 1.4 & $(0.7$ to 2.9$)$ & \\
\hline$>20$ years & 11 & 201 & 0.8 & $(0.5$ to 1.6$)$ & 0.92 \\
\hline \multicolumn{6}{|l|}{ Weaving } \\
\hline Never & 118 & 2063 & 1.0 & Ref & \\
\hline$<10$ years & 9 & 230 & 0.7 & (0.3 to 1.4 ) & \\
\hline $10-20$ years & 17 & 296 & 1.0 & $(0.6$ to 1.8$)$ & \\
\hline$>20$ years & 36 & 594 & 0.9 & $(0.6$ to 1.4$)$ & 0.70 \\
\hline \multicolumn{6}{|l|}{ Cutting/sewing } \\
\hline Never & 164 & 2889 & 1.0 & Ref & \\
\hline$<10$ years & 9 & 85 & 2.3 & (1.1 to 4.6$)$ & \\
\hline $10-20$ years & 3 & 96 & 0.6 & $(0.2$ to 2.0$)$ & \\
\hline$>20$ years & 4 & 113 & 0.7 & $(0.3$ to 2.1$)$ & 0.71 \\
\hline \multicolumn{6}{|l|}{ Maintenance } \\
\hline Never & 174 & 3077 & 1.0 & Ref & \\
\hline$<10$ years & 2 & 48 & 1.0 & (0.2 to 4.1$)$ & \\
\hline $10-20$ years & 2 & 27 & 1.5 & (0.3 to 6.4 ) & \\
\hline$>20$ years & 2 & 31 & 1.4 & $(0.3$ to 6.1$)$ & 0.54 \\
\hline \multicolumn{6}{|c|}{ Administration (non-production) } \\
\hline Never & 130 & 2274 & 1.0 & Ref & \\
\hline$<10$ years & 21 & 339 & 1.4 & (0.9 to 2.3 ) & \\
\hline $10-20$ years & 17 & 268 & 1.5 & $(0.9$ to 2.5$)$ & \\
\hline$>20$ years & 12 & 302 & 0.8 & (0.4 to 1.5 ) & 0.78 \\
\hline
\end{tabular}

ratio test was used to test for exposure-response associations. Associations with smoking, alcohol use, and reproductive factors recorded on the baseline questionnaire were also estimated. Risks associated with various textile manufacturing processes were estimated for "ever" ( $\geqslant 1$ year) versus "never" ( $<$ l year) employed, and by duration of employment $(0,>0-10$ years, $>10-20$ years, $>20$ years $)$. Risks associated with exposures to various dusts and chemical agents, ascertained by linking the women's work history to the JEM, were investigated in the same manner. Cumulative exposures to cotton dust and endotoxin were categorised into quartiles according to the distributions among the subcohort members, with no lag, to estimate exposure-response gradients. The median values of the quartiles were used as weights in the trend tests. We also evaluated risks in relation to cotton dust and endotoxin exposures with lag intervals of 10 years and 20 years to take into account possible disease latency.

\section{RESULTS}

The cancer cases were older than the non-cases (table 1). More cases were former and current smokers compared to non-cases. The HR estimates for current and ex-smokers were 1.9 (95\% CI 1.1 to 5.5 ) and 2.7 (95\% CI 1.0 to 7.2 ), respectively. Therefore, all HR estimates for risk of pancreatic cancer presented were adjusted for age as a continuous variable and smoking status as a categorical variable, as shown in table 1. Alcohol consumption was similar in the two groups, and was not considered further as a possible confounder. More cases had multiple births and earlier age at first live birth than non-cases. This is consistent with the reproductive pattern we observed in this cohort that the older women tend to have more children, and earlier age at first live birth than younger women. After taking age into consideration, cases and non-cases were similar regarding their reproductive factors recorded at baseline. Therefore, none of the reproductive factors was considered as a confounder.

There were no prominent or consistent associations of pancreatic risk with employment in jobs categorised by process type (table 2 ). We observed a 2.3 -fold increased risk of pancreatic cancer among women who worked in cutting and sewing job categories for less than 10 years, but not among women who had worked in these jobs for longer durations.

No associations were found for duration of exposure to dusts, chemicals, or physical agents examined (table 3 ).

In the analysis of quantitative exposures to cotton dust and endotoxin, we observed no associations with cotton and endotoxin exposures when estimating HRs with no lag (table 4 ). When cumulative exposures were lagged by 10 years, we observed no association with cotton exposure, but a significant decreased trend with endotoxin exposure. Furthermore, when cumulative exposures were lagged by 20 years, we observed a significantly reduced risk of pancreatic cancer for women exposed to more than $143.4 \mathrm{mg} / \mathrm{m}^{3} \times$ years of cotton dust and for women exposed to more than $3530.6 \mathrm{EU} / \mathrm{m}^{3} \times$ years of endotoxin. 


\begin{tabular}{|c|c|c|c|c|c|}
\hline Exposure & $\begin{array}{l}\text { Cases } \\
(n=180)\end{array}$ & $\begin{array}{l}\text { Non-cases } \\
(n=3183)\end{array}$ & $H R^{*}$ & $95 \% \mathrm{Cl}$ & $p$ for trend \\
\hline \multicolumn{6}{|l|}{ Wool } \\
\hline Never & 151 & 2733 & 1.0 & Ref & \\
\hline$<10$ years & 2 & 94 & 0.3 & (0.1 to 1.4 ) & \\
\hline $10-20$ years & 6 & 111 & 0.9 & (0.4 to 2.2 ) & \\
\hline$>20$ years & 21 & 245 & 1.4 & (0.9 to 2.3 ) & 0.31 \\
\hline \multicolumn{6}{|l|}{ Silk } \\
\hline Never & 172 & 3019 & 1.0 & Ref & \\
\hline$<10$ years & 2 & 37 & 1.0 & (0.2 to 4.3 ) & \\
\hline $10-20$ years & 1 & 49 & 0.4 & $(0.1$ to 3.1$)$ & \\
\hline$>20$ years & 5 & 78 & 1.1 & (0.4 to 2.8 ) & 0.99 \\
\hline \multicolumn{6}{|c|}{ Synthetic fibre dust } \\
\hline Never & 100 & 1920 & 1.0 & & \\
\hline$<10$ years & 15 & 237 & 1.3 & (0.7 to 2.3 ) & \\
\hline $10-20$ years & 19 & 362 & 1.1 & $(0.7$ to 1.8$)$ & \\
\hline$>20$ years & 46 & 664 & 1.3 & (0.9 to 1.8 ) & 0.21 \\
\hline \multicolumn{6}{|l|}{ Non-textile dust } \\
\hline Never & 147 & 2658 & 1.0 & Ref & \\
\hline$<10$ years & 7 & 201 & 0.6 & (0.3 to 1.4$)$ & \\
\hline $10-20$ years & 15 & 163 & 1.5 & (0.9 to 2.6$)$ & \\
\hline$>20$ years & 11 & 161 & 1.2 & (0.6 to 2.3 ) & 0.33 \\
\hline \multicolumn{6}{|l|}{ Solvents } \\
\hline Never & 165 & 2724 & 1.0 & Ref & \\
\hline$<10$ years & 4 & 170 & 0.5 & (0.2 to 1.4$)$ & \\
\hline $10-20$ years & 8 & 139 & 1.1 & (0.5 to 2.2$)$ & \\
\hline$>20$ years & 3 & 150 & 0.4 & $(0.1$ to 1.3$)$ & 0.12 \\
\hline \multicolumn{6}{|l|}{ Lubricants } \\
\hline Never & 62 & 1210 & 1.0 & & \\
\hline$<10$ years & 20 & 330 & 1.2 & (0.7 to 2.0$)$ & \\
\hline $10-20$ years & 27 & 496 & 1.0 & (0.7 to 1.7 ) & \\
\hline$>20$ years & 71 & 1147 & 1.0 & (0.7 to 1.4 ) & 0.72 \\
\hline \multicolumn{6}{|l|}{ Metals } \\
\hline Never & 171 & 2956 & 1.0 & Ref & \\
\hline$<10$ years & 2 & 87 & 0.5 & (0.1 to 2.1 ) & \\
\hline $10-20$ years & 5 & 58 & 1.5 & $(0.6$ to 3.9$)$ & \\
\hline$>20$ years & 2 & 82 & 0.6 & (0.1 to 2.4 ) & 0.73 \\
\hline \multicolumn{6}{|c|}{ EMF or non-ionising radiation } \\
\hline Never & 52 & 1016 & 1.0 & Ref & \\
\hline$<10$ years & 24 & 343 & 1.4 & (0.8 to 2.3 ) & \\
\hline $10-20$ years & 29 & 576 & 1.0 & (0.6 to 1.6$)$ & \\
\hline$>20$ years & 75 & 1248 & 1.0 & $(0.7$ to 1.4$)$ & 0.63 \\
\hline
\end{tabular}

*Age (continuous) and smoking status (categories) adjusted hazard ratio.

Additionally, there were statistically significant decreasing trends of risk with estimated cumulative exposures to these two agents when a 20 year lag was imposed. Collinearity between cotton dust and endotoxin cumulative exposures precluded mutual adjustment of risk trends. The correlation coefficient between cotton dust and endotoxin exposures was 0.57 .

\section{DISCUSSION}

The most prominent findings of this study of female workers in the Shanghai textile industry were inverse gradients of pancreatic cancer associated with cumulative exposures to cotton dust and endotoxin when exposures were lagged 20 years. There were no other noteworthy findings for employment in broad job categories or for exposures to other textile industry dusts, chemicals, or physical agents.

There are several strengths to this study. It is the largest cohort study of confirmed incident pancreatic cancer conducted to date that has focused on textile exposures among female workers. Trained field staff collected detailed information on lifetime jobs in the textile industry for each woman. The comprehensive information on production processes, workshops, and measurement of hazardous exposures since the establishment of each factory collected by local industrial hygienists provided more extensive, detailed, and specific exposure data than those in previous studies on occupational risk for pancreatic cancer. Information on smoking status, alcohol consumption, and reproductive risk factors was available to be investigated as potential confounding factors.

The study also has several limitations. Quantitative historical measurements of exposures for most agents of interest were not available. Relying on duration of exposure to estimate dose-response relations limited our ability to detect possible differences in risk related to exposure intensities. Although there was the potential for confounding between job categories if women held several different textile industry jobs, there was relatively little mobility between sectors or factories before 1994. Moreover, women usually held the same job in the same factory for their entire working career in this cohort. Women on average held two jobs in this study. We also restricted our analyses to women who only worked in one job. The results were not materially different. The study subjects are women who enrolled in the BSE trial. Therefore, cases that occurred before the BSE trial were not included. It is possible that we may have underestimated some associations because cases in this study may represent people who are resistant to pancreatic cancer. The magnitude of such bias is unclear.

Smoking is a well established risk factor for pancreatic cancer. We observed increased risks among smokers, which was consistent with previous findings. ${ }^{29}$ However, the low smoking prevalence in this cohort of women provided us an opportunity to investigate possible effects on risk of occupational exposures largely in the absence of smoking, which minimised confounding. An excess risk of pancreatic cancer 
Table 4 Hazard ratio estimates of pancreatic cancer in relation to cumulative quantitative cotton dust and endotoxin exposures

\begin{tabular}{|c|c|c|c|c|c|}
\hline Exposure & $\begin{array}{l}\text { Cases } \\
(n=180)\end{array}$ & $\begin{array}{l}\text { Non-cases } \\
(n=3183)\end{array}$ & $\mathrm{HR}^{*}$ & $95 \% \mathrm{Cl}$ & $p$ for trend $t$ \\
\hline \multicolumn{6}{|c|}{$\begin{array}{l}\text { Cotton dust }\left(\mathrm{mg} / \mathrm{m}^{3} \times \text { years }\right) \\
\text { No lag }\end{array}$} \\
\hline None & 54 & 1016 & 1.0 & Ref & \\
\hline$>0$ to 55.9 & 30 & 542 & 1.1 & (0.7 to 1.7 ) & \\
\hline$>55.9$ to 97.0 & 27 & 542 & 0.9 & (0.6 to 1.4$)$ & \\
\hline$>97.0$ to 143.4 & 36 & 540 & 1.0 & $(0.6$ to 1.6$)$ & \\
\hline$>143.4$ & 33 & 543 & 0.9 & (0.6 to 1.4 ) & 0.60 \\
\hline \multicolumn{6}{|l|}{10 year lag } \\
\hline None & 55 & 1026 & 1.0 & Ref & \\
\hline$>0$ to 55.9 & 33 & 611 & 1.1 & (0.7 to 1.7 ) & \\
\hline$>55.9$ to 97.0 & 30 & 520 & 1.0 & (0.6 to 1.6$)$ & \\
\hline$>97.0$ to 143.4 & 30 & 509 & 0.8 & (0.5 to 1.3$)$ & \\
\hline$>143.4$ & 32 & 517 & 0.9 & (0.6 to 1.4 ) & 0.34 \\
\hline \multicolumn{6}{|l|}{20 year lag } \\
\hline None & 61 & 1198 & 1.0 & Ref & \\
\hline$>0$ to 55.9 & 41 & 637 & 1.2 & (0.8 to 1.8$)$ & \\
\hline$>55.9$ to 97.0 & 31 & 455 & 1.0 & (0.6 to 1.5$)$ & \\
\hline$>97.0$ to 143.4 & 27 & 457 & 0.7 & $(0.5$ to 1.2$)$ & \\
\hline$>143.4$ & 20 & 436 & 0.6 & $(0.3$ to 0.9$)$ & 0.006 \\
\hline \multicolumn{6}{|c|}{$\begin{array}{l}\text { Endotoxin }\left(E U / m^{3} \times \text { years) }\right. \\
\text { No laq }\end{array}$} \\
\hline None & 54 & 916 & 1.0 & Ref & \\
\hline$>0$ to 1517.4 & 32 & 530 & 1.0 & $(0.7$ to 1.6$)$ & \\
\hline$>1517.4$ to 2430.0 & 36 & 529 & 1.1 & $(0.7$ to 1.6$)$ & \\
\hline$>2430.0$ to 3530.6 & 24 & 530 & 0.6 & $(0.4$ to 1.1$)$ & \\
\hline$>3530.6$ & 30 & 529 & 0.8 & $(0.5$ to 1.2$)$ & 0.12 \\
\hline \multicolumn{6}{|l|}{10 year lag } \\
\hline None & 55 & 926 & 1.0 & Ref & \\
\hline$>0$ to 1517.4 & 36 & 627 & 1.1 & (0.7 to 1.7$)$ & \\
\hline$>1517.4$ to 2430.0 & 35 & 501 & 1.0 & $(0.7$ to 1.6$)$ & \\
\hline$>2430.0$ to 3530.6 & 23 & 479 & 0.6 & (0.4 to 1.1$)$ & \\
\hline$>3530.6$ & 27 & 501 & 0.7 & (0.4 to 1.1$)$ & 0.04 \\
\hline \multicolumn{6}{|l|}{20 year lag } \\
\hline None & 61 & 1093 & 1.0 & Ref & \\
\hline$>0$ to 1517.4 & 46 & 663 & 1.2 & (0.8 to 1.8 ) & \\
\hline$>1517.4$ to 2430.0 & 35 & 462 & 1.0 & (0.6 to 1.5$)$ & \\
\hline$>2430.0$ to 3530.6 & 15 & 402 & 0.4 & $(0.2$ to 0.8$)$ & \\
\hline$>3530.6$ & 19 & 414 & 0.5 & $(0.3$ to 0.9$)$ & $<0.001$ \\
\hline
\end{tabular}

in textile workers has been reported in several studies. ${ }^{12} 152236$ Zhang et al observed an increased risk of pancreatic cancer for textile sewing machine operators, with the greatest risk among workers with more than 10 years of employment in this occupation. ${ }^{37}$ We observed an excess risk of pancreatic cancer for women who worked in cutting and sewing job categories for less than 10 years, but not for more than 10 years. This could be a chance finding because the number of women who have worked in cutting/sewing was small. An association with cutting and sewing jobs needs to be investigated further before any firm conclusion can be drawn.

An increased risk of pancreatic cancer in men exposed to cotton dust has been reported previously in a hospital based case control study in Louisiana. The association was based on only 14 exposed cases and four exposed controls. ${ }^{36}$ In contrast, we observed an inverse association between risk of pancreatic cancer and cotton dust and endotoxin exposure. We repeated the analyses restricting to women who have never smoked, and the results did not change. Cotton dust is frequently contaminated with Gram negative bacteria that produce endotoxin. Collinearity between cotton dust and endotoxin exposure precluded mutually adjusted analyses that might reveal whether endotoxin or some other component of cotton dust was the more relevant factor. Insofar as endotoxin is probably the most biologically active agent in cotton dust, it would appear to be the most plausible factor. Enhanced immune surveillance due to endotoxin exposure has been hypothesised as the mechanism by which cotton dust might reduce risk of lung cancer. ${ }^{38}$ It is possible that exposure to endotoxin may reduce the risk of development of pancreatic cancer through the same mechanism. Alternatively, the decreased risk of pancreatic cancer with endotoxin was only observed when exposure was lagged by 20 years, which may indicate an early stage anticarcinogenic action.

Increased risk of pancreatic cancer has been associated with occupations in the chemical industry, ${ }^{45}$ printing, ${ }^{6-8}$ and metal industry. ${ }^{10}$ Chemicals involved in these industries may also be present in textile industry. However, we did not observe any associations between risk of pancreatic cancer and a variety of these chemicals.

In summary, we observed that exposures to cotton dust and endotoxin 20 years in the past were associated with a decreased risk of pancreatic cancer. To our knowledge, these associations have not been observed previously. With the large number of textile exposures considered, we believe that these results should be replicated by others before making a firm conclusion of their possible effects on pancreatic cancer.

\section{ACKNOWLEDGEMENTS}

This research was supported by grant R01CA80180 from the US National Cancer Institute, National Institutes of Health. We thank Wen Wan Wang, the Shanghai study manager and Drs Dai He Lian, Wang Zhu Ming, Qi A Zhen, Wang XiaMing, Xiang Wei Ping, and Li Yu Fang for their extensive efforts in collecting factory information; the 30 field workers for collecting women's personnel records and confirming diagnoses; and Georgia Green, Shirley Zhang, Richard Gandolfo, Ted Grichuhin for their technical and administrative support. We are grateful to Dr David Christiani for providing 


\section{Main messages}

- Pancreatic cancer risk in female textile workers in Shanghai, China was inversely associated with exposures to cotton dusts and endotoxin when exposures were lagged 20 years.

- Employment in the textile industry or exposure to other textile industry dusts, chemicals, or physical agents were not associated with risk of pancreatic cancer.

\section{Policy implications}

- Occupational exposures do not appear to contribute to the risk of pancreatic cancer.

- The associations of exposure to cotton dust and endotoxin with risk of pancreatic cancer should be replicated by others before making any firm conclusions.

exposure data that improved the cotton dust and endotoxin exposure assessments.

\section{Authors' affiliations}

W Li, R M Ray, K J Wernli, Z Feng, D B Thomas, H Checkoway, Public Health Sciences, Fred Hutchinson Cancer Research Center, Seattle, WA, USA

D L Gao, Department of Epidemiology, Zhong Shan Hospital Cancer Center, Shanghai, China

W Li, N S Seixas, J E Camp, K J Wernli, Z Feng, D B Thomas,

H Checkoway, School of Public Health and Community Medicine,

University of Washington, Seattle, WA, USA

G Astrakianakis, Occupational Health and Safety Agency for Healthcare, Vancouver, BC, Canada

E D Fitzgibbons, Group Health Center for Health Studies, Seattle, WA, USA

\section{REFERENCES}

1 American Cancer Society. Cancer facts and figures-2003. Atlanta, GA: American Cancer Society Inc, 2003:4

2 IAfRoC. IARC monographs on the evaluation of the carcinogenic risk of chemicals to humans. IARC 1986:279-84.

3 Berrington de Gonzalez A, Sweetland S, Spencer E. A meta-analysis of obesity and the risk of pancreatic cancer. Br J Cancer 2003;89:519-23.

4 Bond GG, Reeve GR, OHt MG, et al. Mortality among a sample of chemical company employees. Am J Ind Med 1985;7:109-21.

5 Hanis NM, Holmes TM, Shallenberger G, et al. Epidemiologic study of refinery and chemical plant workers. J Occup Med 1982;24:203-12.

6 Zoloth SR, Michaels DM, Villalbi JR, et al. Patterns of mortality among commercial pressmen. J Natl Cancer Inst 1986;76:1047-51.

7 Alguacil J, Pollan M, Gustavsson P. Occupations with increased risk of pancreatic cancer in the Swedish population. Occup Environ Med 2003;60:570-6.

8 McNamee R, Braganza JM, Hogg J, et al. Occupational exposure to hydrocarbons and chronic pancreatitis: a case-referent study. Occup Environ Med 1994;51:631-7.
9 Silverstein M, Park R, Marmor M, et al. Mortality among bearing plant workers exposed to metalworking fluids and abrasives. J Occup Med 1988:30:706-14.

10 Mur JM, Moulin JJ, Meyer-Bisch C, et al. Mortality of aluminium reduction plant workers in France. Int J Epidemiol 1987;16:257-64.

11 Magnani C, Coggon D, Osmond C, et al. Occupation and five cancers: a case-control study using death certificates. Br J Ind Med 1987;44:769-76.

12 Pietri F, Clavel F, Auquier A, et al. Occupational risk factors for cancer of the pancreas: a case-control study. Br J Ind Med 1990;47:425-8.

13 Costantini AS, Paci E, Miligi L, et al. Cancer mortality among workers in the Tuscan tanning industry. Br J Ind Med 1989;46:384-8.

14 Partanen T, Kauppinen T, Degerth R, et al. Pancreatic cancer in industrial branches and occupations in Finland. Am J Ind Med 1994:25:851-66.

15 Alguacil J, Porta M, Benavides FG, et al. Occupation and pancreatic cancer in Spain: a case-control study based on job titles. PANKRAS II Study Group. Int J Epidemiol 2000:1004-13.

16 Hansen ES. Mortality of auto mechanics. A ten-year follow-up. Scand J Work Environ Health 1989;15:43-6.

17 Alavanja MC, Blair A, Masters MN. Cancer mortality in the U.S. flour industry. J Natl Cancer Inst 1990;82:840-8.

18 Blair A, Dosemeci M, Heineman EF. Cancer and other causes of death among male and female farmers from twenty-three states. Am J Ind Med 1993:23:729-42.

19 Cerhan JR, Cantor KP, Williamson K, et al. Cancer mortality among lowa farmers: recent results, time trends, and lifestyle factors (United States). Cancer Causes Control 1998:9:311-19.

20 Fryzek JP, Garabrant DH, Harlow SD, et al. A case-control study of selfreported exposures to pesticides and pancreas cancer in southeastern Michigan. Int J Cancer 1997;72:62-7.

21 Ojajarvi IA, Partanen TJ, Ahllbom A, et al. Occupational exposures and pancreatic cancer: a meta-analysis. Occup Environ Med 2000;57:316-24.

22 Olsen JH, Jensen OM. Occupation and risk of cancer in Denmark. An analysis of 93,810 cancer cases, 1970-1979. Scand J Work Environ Health 1987; 13(Suppl 1):1-91.

23 Ji BT, Silverman DT, Dosemeci $M$, et al. Occupation and pancreatic cancer risk in Shanghai, China. Am J Ind Med 1999:35:76-81.

24 Thomas DB, Gao DL, Self SG, et al. Randomized trial of breast selfexamination in Shanghai: methodology and preliminary results. J Natl Cancer Inst 1997;89:355-65

25 Thomas DB, Gao DL, Ray RM, et al. Randomized trial of breast selfexamination in Shanghai: final results. J Natl Cancer Inst 2002;94:1445-57.

26 Wernli KJ, Ray RM, Gao DL, et al. Cancer among women textile workers in Shanghai, China: overall incidence patterns, 1989-1998. Am J Ind Med 2003;44:595-9.

27 Borgan O, Langholz B, Samuelsen SO, et al. Exposure stratified case-cohort designs. Lifetime Data Anal 2000;6:39-58.

28 Camp JE, Seixas NS, Wernli K, et al. Development of a cancer research study in the Shanghai textile industry. Int J Occup Environ Health 2003;9:347-56.

29 Wernli KJ, Astrakianakis G, Camp J, et al. Development of a job exposure matrix (JEM) for the textile industry in Shanghai, China. J Occup Environ Health 2006 (in press).

30 Astrakianakis G, Seixas NS, Camp JE, et al. Modeling, estimation and validation of cotton dust and endotoxin exposures in Chinese textile operations. Ann Occup Hyg 2006 (in press).

31 Christiani DC, Ye TT, Zhang S, et al. Cotton dust and endotoxin exposure and long-term decline in lung function: results of a longitudinal study. Am J Ind Med 1999;35:321-31.

32 Christiani DC, Ye TT, Wegman DH, et al. Cotton dust exposure, across-shift drop in FEVI, and five-year change in lung function. Am J Respir Crit Care Med 1994;150:1250-5.

33 Olenchock SA, Christiani DC, Mull JC, et al. Airborne endotoxin concentrations in various work areas within two cotton textile mills in the People's Republic of China. Biomed Environ Sci 1990;3:443-51.

34 Astrakianakis $\mathbf{G}$. Cotton dust, endotoxin exposure and the risk of lung cancer among female textile workers in Shanghai. Doctoral dissertation, University of Washington, 2005 (in press).

35 Barlow WE, Ichikawa L, Rosner D, et al. Analysis of case-cohort designs. J Clin Epidemiol 1999:52:1165-72.

36 Falk RT, Pickle LW, Fontham ET, et al. Occupation and pancreatic cancer risk in Lovisiana. Am J Ind Med 1990;18:565-76.

37 Zhang Y, Cantor KP, Lynch CF, et al. Occupation and risk of pancreatic cancer: a population-based case-control study in iowa. J Occup Environ Med 2005:47:392-8.

38 Enterline PE, Sykora JL, Keleti G, et al. Endotoxins, cotton dust, and cancer. Lancet $1985 ; 2: 934-5$. 